\title{
QUANTITATIVE RELATIONSHIP BETWEEN MARINE AND FRESHWATER PREYS AND PREDATORS AS DETERMINED BY $\mathrm{C}^{14}$ LABELED GLUCOSE
}

\author{
Yoshio Hryama and Ravindra Pratap SINGH* \\ (Received May 30, 1966)
}

As it was shown in the previous papers ${ }^{11}{ }^{21}$ using either $\mathrm{P}^{32}$ or $\mathrm{S}^{35}$ that the fishes have a higher absorption rate for their own muscle, the following experiment was performed using $\mathrm{C}^{4}$ labeled glucose as a tracer to verify the above mentioned result.

\section{Materials}

Nuclide: In this experiment $C^{14}$ (weak beta emitter having a half life of 5700 years) was used in the form of glucose.

Predators: Two species of marine and two species of freshwater fishes were used as a predator as listed in the Table 1.

Table 1. List of the fishes used in the experiment.

\begin{tabular}{|c|c|c|c|c|}
\hline No. & Scientific name & Common name & Feeding habit & $\begin{array}{c}\text { Size } \\
\text { (B.L. } \mathrm{cm} \text { ) }\end{array}$ \\
\hline 1. & Chasmichthys gulosus & Goby & Carnivorous & $4.0-5.0$ \\
\hline 2. & Rudarius ercodes & File fish & Omnivorous & $2.0-3.5$ \\
\hline 3. & Oryzias latipes & Minnow & Plankton feeder & $3.0-3.5$ \\
\hline 4. & Carassitus auratus & Gold fish & Omnivorous & $5.0 \cdots 7.0$ \\
\hline
\end{tabular}

Food: Muscle of the above mentioned four species of fishes were used as a food to all the fishes.

\section{Method}

Preparation of the food and determination of the time to reach maximum absorption: $0.02 \mu \mathrm{c}$ of labeled glucose was orally administered to the fishes which had been starved for 24 hours and they were kept in a flask containing $\mathrm{CO}_{2}$ free water, sealed with rubber stopper having a right angle bent glass tube and soda lime tube. The fishes were sacrificed at different time intervals, i.e., 5 minutes, 2 hours, and 4 hours and organs such as intestine, scale, liver, muscle, head and vertebrae were separated out for radioassay. After knowing the distribution and fate of radioactive glucose, $0.2 \mu \mathrm{c} \mathrm{C}^{14}$ glucose was administered and fishes were sacrificed after 30

* Department of Fisheries, Faculty of Agriculture, University of Tokyo, 
minutes. A portion of muscle was removed and dried up in vacuo $0.2 \mathrm{ml}$ of prepared food (suspension of labeled muscle powcler) containing about $1300 \mathrm{cpm}$ was given to all the fishes and they were sacrificed at different time intervals i.e., 1, 2, 4, 6, 12, and 24 hours to measure the radioactivity absorbed by the body and retained in the intestine. The radioactivity was done as given below. At the same time the water of the flask was acidified with the few drops of sulfuric acid. The whole water of the flask was aerated to expel $\mathrm{CO}_{2}$ exhaled by the fish which was absorbed by barium hydroxide and radioactivity was measured by low back ground G. M. counter for ten minutes each. The time limit 4 hours was fixed after knowing the process of digestion and absorption by an initial experiment using gold fish as food as it is shown in the Figure 1.

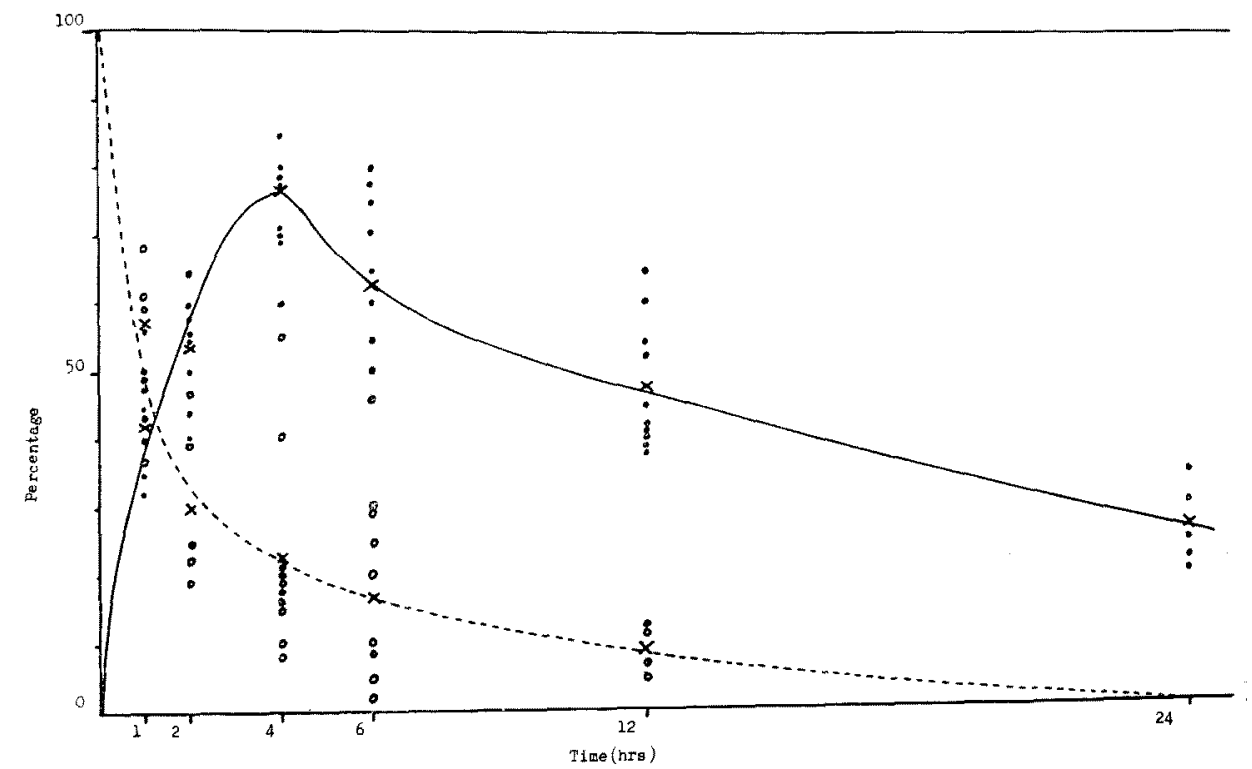

Fig. 1. Percentage of $\mathrm{C}^{14}$ absorbed by body (continuous line) and digestive canal (dotted line) in relation to time.

The figure shows that the absorption of the food labeled with $\mathrm{C}^{14}$ taken in by the fishes as food reached the peak at four hours after feeding.

Absorption rates in combinations of food and predators: Different kinds of fish muscle (in the form of liquid) were administered to the different kinds of fishes. These fishes were kept in the above mentioned type of flask. Four hours after feeding they were sacrificed and their radioassay was done as described below. The ratio of the amount of $\mathrm{C}^{14}(\mathrm{cpm})$ found in the whole body of the single individual of the predator to the amount of $\mathrm{C}^{14}(\mathrm{cpm})$ in the fed food was taken as the absorption rate of that individual as given by the following formula. 
Absorption rate $=\frac{\text { Total radioactivity in the whole body }(\mathrm{cpm})}{\text { Total radioactivity in the fed food }(\mathrm{cpm})} \times 100$.

Radioassay of $\mathrm{C}^{14}$ in the samples: Wet combustion by Van Slyke Folch's method have been adopted here a convinient way to oxidize the samples for carbon radioassay. For this purpose various oxidizing agents had been proposed; the Van Slyke Folch's method was considered to be closest approach to ideal reagent and it has been found to give excellent analytical values for carbon. A convenient apparatus so-called the Barker's apparatus for carrying out small scale oxidation when it was desired to collect barium carbonate is shown in the Figure 2.

Sample to be oxidized was placed in a combustion tube A, and a small beaker B was filled with $5 \mathrm{ml}$ oxidant. D received $25 \mathrm{ml}$ of $0.25 \mathrm{~N}$ barium hydroxide. The

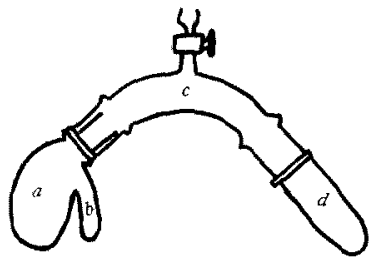

Fig. 2. Improved apparatus for wet combustion. whole apparatus was assembled and evacuated through the vaccum pump. This opertion was performed by opening and closing the stop cock, so that all the air swept out from the apparatus. The combusion tube was carefully revolved until the liquid reagent in $B$ was transferred to $\mathrm{A}$; the mixture was boiled gently with a small flame for ten to fifteen minutes. The assembly was allowed to stand for ten minutes more to insure complete absorption of carbon dioxide into alkali solution. Then barium carbonate was collected on weighed filter paper as given below. Here filtration method was adopted to get uniform precipitate of barium carbonate. The precipitate was washed with $\mathrm{CO}_{2}$ free hot water and ethyl alchol; filter paper with barium barbonate was placed on the planchet. After drying radioactivity was measured by low back ground G. M. counter for ten minutes and obtained radioactivity was corrected for self absorption.

\section{Results and díscussion}

Fate of labeled glucose: The distribution of orally administered $\mathrm{C}^{14}$ labeled glucose was very quick because within a few minutes all the parts i.e., scale, skin, liver, fin, head, vertebrae and the gills showed the radioactivity as mentioned in the Table 2. It was considered that glucose was utilized as a major fuel of the body by all the tissues and it went into different parts of the body directly through blood stream.

At the beginning vertebrae and its adhered blood vessel contained the highest concentration of radioactivity but four hours after administration it depleted almost to the vanishing stage. The same tendency was indicated by the head of the fishes because carbohydrate especially the glucose is the main source of its energy. Administered $\mathrm{C}^{14}$ glucose was given out of the body in the form of carbon dioxide. 
Table 2. Concentration (cpm/g of wet tissue) of activity in the different tissue at a different intervals of time after the administration of $.02 \mu c$ of radioactive glucose.

\begin{tabular}{|c|c|c|c|c|}
\hline \multirow{2}{*}{ No. } & \multirow{2}{*}{ Name of the organ } & \multicolumn{3}{|c|}{ Time after administration } \\
\hline & & 5 minutes & 2 hours & 4 hours \\
\hline 1. & Scale & 15,200 & 31,700 & 2,530 \\
\hline 2. & Fin & 14,500 & 5,620 & 4,280 \\
\hline 3. & Skin & 2,290 & 8,970 & 1,350 \\
\hline 4. & Liver & 18,600 & 6,460 & 2,700 \\
\hline 5. & Intestine & 63,500 & 2,630 & 1,590 \\
\hline 6. & Gill & 7,750 & 5,700 & 1,150 \\
\hline 7. & Muscle & 24,900 & 7,930 & 1,840 \\
\hline 8. & Vertebrae & 63,800 & 26,500 & 0 \\
\hline 9. & Head & 23,900 &, 330 &, 150 \\
\hline
\end{tabular}

Absorption rates obtained with the help of $\mathrm{C}^{14}$ labeled glucose: The absorption of the labeled food (fish muscle) with $\mathrm{C}^{14}$ in the fishes reached the peak about four hours after feeding as shown in the Figure 1.

Table 3. Absorption rate obtained using the radioisotope $\mathrm{C}^{14}$ (percentage)

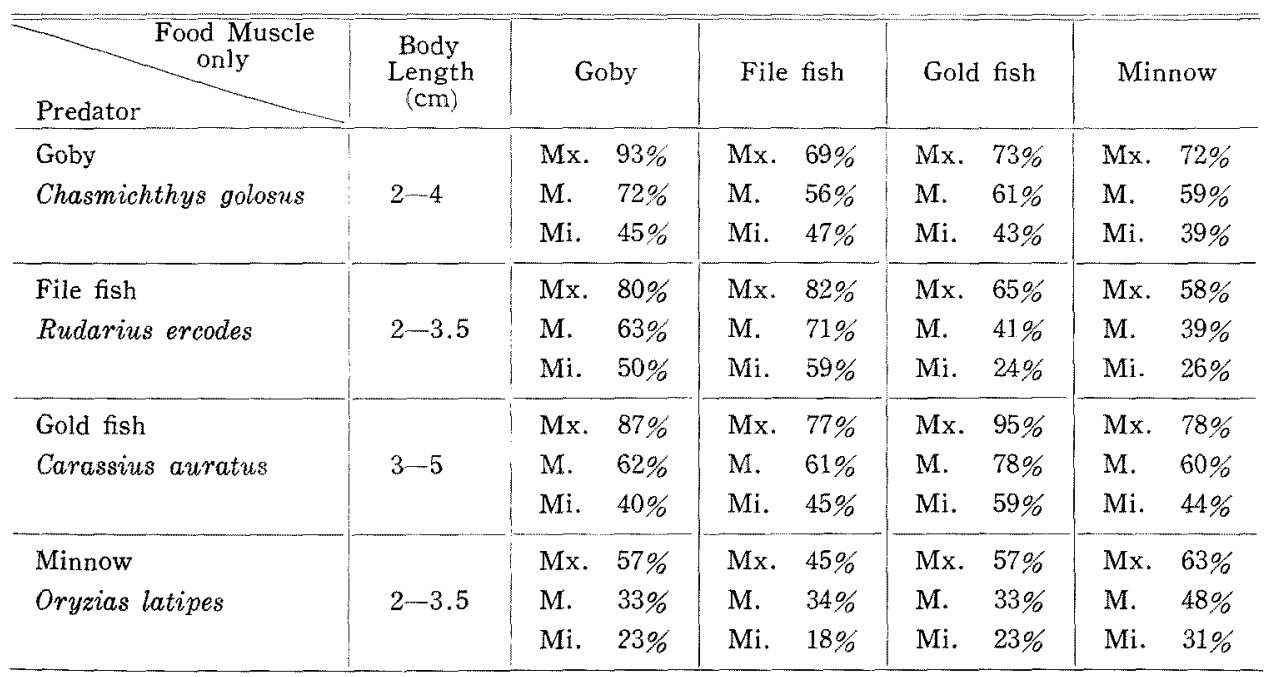

Note: $-\mathrm{Mx}=$ Maximum absorption rate among the ten individuals of predator. $M=$ Mean absorption rate of ten individuals of predator.

$\mathrm{Mi}=$ Mininum absorption rate of ten individuals of predator.

From the Table 3 showing the absorption rates-maximum, minimum and mean of the ten individuals, which was obtained as a result of this experiment one could observe the following phenomena.

Plankton feeding fish shows lower absorption rates than that for omnivorous and 
carnivorous fishes when $\mathrm{C}^{14}$ labeled muscle was used.

From the same table and Fig. 3 it can be concluded that when fishes were fed with the same muscle as predator the absorption rates were high but when the fishes were fed with muscle of different species of fishes the absorption rates were lower than the former.
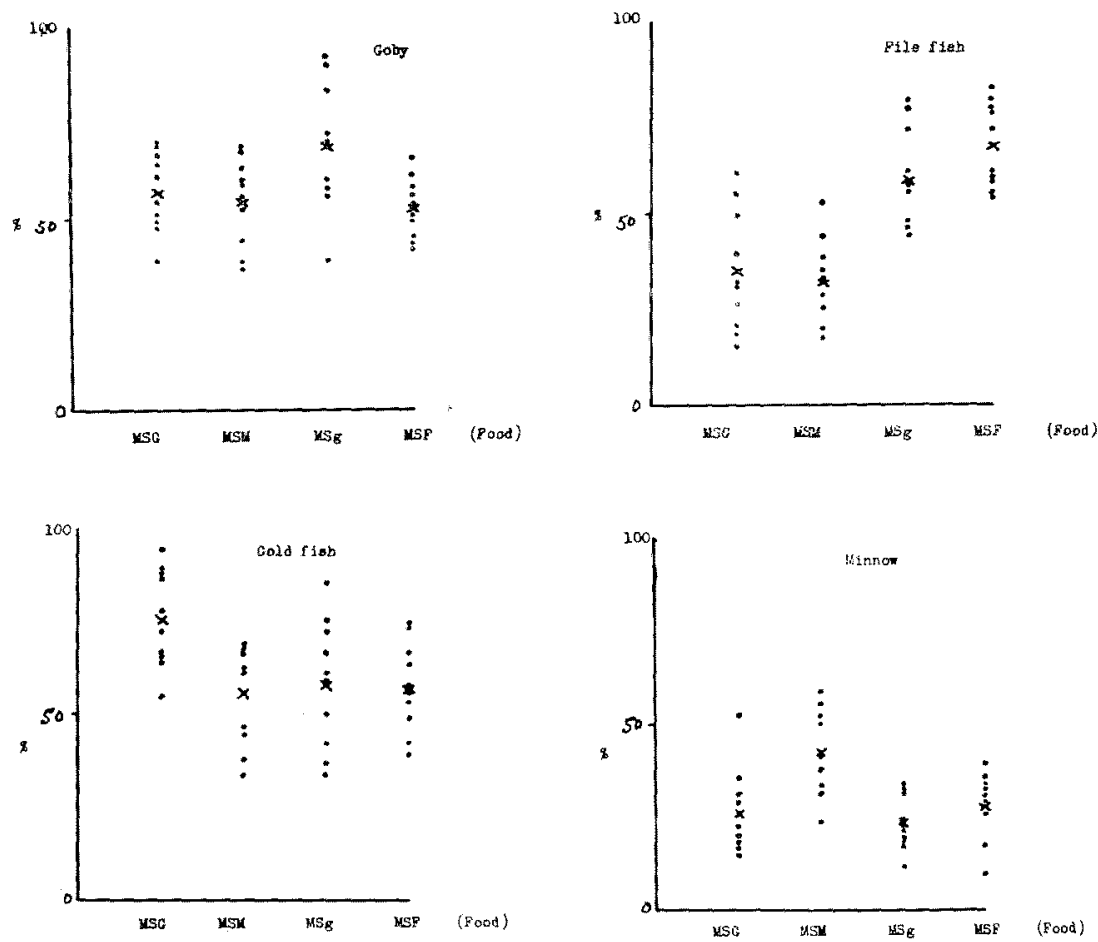

Fig. 3. Comparison of the absorption rates of each predator, using muscle of different types of fishes as food. MSG.-Muscle of Goldfish. MSM.-Muscle of Minnow.

MSg.--Muscle of Goby. MSF.-Muscle of File fish.

Besides that shown in the Table 3 a series of the experiments were performed to find out the difference in the absorption rates when file fish were fed on its different parts such as scale, skin, muscle and bone. The absorption rates were $40 \%, 65 \%, 71 \%$, and $28 \%$ respectively.

Using $\mathrm{P}^{32}$ and $\mathrm{S}^{35}$ as a tracer of biological mass it was found that when the fishes were fed their own muscle the absorption rate was high. This fact coincides with that obtained in $\mathrm{C}^{14}$ experiment 


\section{References}

1) B. Agraham and Y. Hiyama: This Bull. 28 1097 1098 (1962).

2) Y. HIYAMA and R.P. Singh: Ibid., 32, 705 709.

3) M. Calvin, C. Heiderberger, J. C. Reid, B. M. Tolbert and P. F. Yankwich: Isotopic Carbon (John Wiley and Sons, INC., New York, London) (1949).

4) S. Mitsul and K. Kurihara: Soil and Plant Food, 3, Oct. $59 \sim 64$ (1957). 